\title{
LA INCLUSIÓN: UN RETO PARA EL SISTEMA EDUCATIVO COSTARRICENSE
}

\author{
Grettel Quijano Chacón \\ Estudiante de la Maestría en Planificación Curricular \\ Universidad de Costa Rica \\ San José, Costa Rica
}

Recibido: 27-XI-2007 • Aceptado 9-IV-2008 • Corregido 3-VI-2008

\begin{abstract}
Resumen: Este artículo se escribe con referencia a una serie de aspectos relacionados con la inclusión educativa, con el propósito de hacer conciencia en la comunidad educativa y en la sociedad costarricense, acerca de la importancia de llevar a la práctica actitudes de respeto, tolerancia y solidaridad hacia los estudiantes y las estudiantes con necesidades educativas especiales asociadas a discapacidad intelectual, lo que posibilita la construcción de una sociedad justa y equitativa.

Para que la inclusión sea una realidad, es necesario que exista una responsabilidad compartida, en la que cada uno asuma sus responsabilidades con el fin de mejorar la calidad de vida de dicha población.
\end{abstract}

Palabras claves: Inclusión educativa, estudiantes con necesidades educativas especiales, discapacidad intelectual.

\begin{abstract}
This article it written in reference to a series of aspects related to the educative inclusion, in order to make conscience in the educative community and the Costa Rican society, about the importance of taking into practices attitudes of respect, tolerance and solidarity towards the students with special educative necessities associated to intellectual disability, which seeks the construction of a fair and equitable society. For inclusion to be a reality it is necessary that a shared responsibility exists in the which each one assumes its responsibilities with the purpose of improving the quality of life of this population.
\end{abstract}

Key words: Inclusion, students with special educative necessities, intellectual disability.

\section{Introducción}

El sistema educativo en los últimos años se ha visto en la necesidad de integrar en las aulas regulares de primaria, a estudiantes con necesidades educativas especiales asociadas a discapacidad intelectual; lo cual obedece en gran medida a los procesos de globalización, que conllevan a una mayor apertura y consecuentemente a cambios en muchas áreas; una de ellas la de educación especial.

El propósito de este artículo es informar y concienciar a los docentes de aula regular, de cómo los estudiantes con necesidades educativas especiales, asociadas a discapacidad intelectual, pueden y deben ser atendidos en ambientes educativos regulares.

Las personas con necesidades educativas especiales asociadas a discapacidad intelectual tienen derecho a la educación y que esta se les brinde en el ambiente menos restringido posible, de manera que tengan los mismos derechos que el resto de la población estudiantil.

Para el desarrollo de este artículo se parte de que la inclusión educativa de 
estudiantes con necesidades educativas especiales asociadas a discapacidad intelectual es una responsabilidad conjunta de docentes regulares, docentes especiales, personal administrativo, familia y es un reto para el sistema educativo costarricense y para la sociedad.

Al referirse al tema de inclusión educativa es necesario tomar en cuenta los principios de normalización, integración, sectorización e individualización de la enseñanza, en la atención educativa de los estudiantes y las estudiantes con necesidades educativas especiales asociadas a discapacidad intelectual, de forma tal que se haga efectivo el derecho a una educación flexible y de calidad.

A pesar de que se ha hablado mucho del tema de inclusión educativa en los últimos años, aún existen inquietudes $\mathrm{y}$ quejas por parte de los docentes de enseñanza regular con respecto a la falta de información y de pautas que clarifiquen sus responsabilidades en el proceso de inclusión, igualmente del acompañamiento que debería existir por parte de los docentes de enseñanza especial, los padres y madres de familia, la comunidad educativa y la sociedad en general.

Es conveniente mencionar que la inclusión educativa va más allá de tratados, convenciones internacionales y leyes, si bien es cierto, ellas legitiman los derechos que tienen las personas que presentan algún tipo de discapacidad; lo que en realidad se necesita, es un cambio de actitud hacia las personas diferentes.

En el proceso de inclusión educativa la responsabilidad se comparte, cada uno de los entes involucrados asume las funciones que le competen y las lleva a cabo de forma adecuada. Cada persona asume aquello para lo cual es competente y lo desarrolla con una actitud positiva, de entrega y de compromiso.

El éxito de la inclusión educativa no depende de unos pocos o de los que están capacitados, es una tarea compartida, para la cual se requiere de un trabajo en equipo y de calidad, que redunde en beneficio de los estudiantes y las estudiantes con necesidades educativas especiales asociadas a discapacidad intelectual.

Para el sistema educativo costarricense la inclusión de estudiantes con necesidades educativas especiales asociadas a discapacidad intelectual, es un reto en el que ya se han dado los primeros pasos, sin embargo, se necesita de un gran compromiso, sobre todo de los docentes de educación regular, ya que de ellos dependerá en gran parte el éxito o fracaso del proceso de inclusión.

El desarrollo de la educación especial en Costa Rica ha pasado por varias etapas, desde la creación de escuelas de enseñanza especial hasta la integración de estudiantes que presentan algún tipo de discapacidad en las aulas regulares de primero y segundo ciclos de la educación general básica.

Lo anterior no significa que la inclusión educativa sea una realidad en la totalidad de centros educativos, o que la misma se esté realizando de la mejor manera, ya que son muy pocas las instituciones que tienen de forma clara y concreta su misión, visión y normativa interna; en las que se establece claramente la atención de las necesidades educativas especiales.

Para este artículo se realiza una indagación bibliográfica acerca del tema de la inclusión educativa de estudiantes con necesidades educativas especiales asociadas a discapacidad intelectual, la cual se ha limitado a la atención individualizada del discente; situación muy relacionada con el modelo tradicional de la educación especial, centrado en el déficit y que deja de lado la socialización.

Además se puntualiza en la responsabilidad compartida y el trabajo en equipo, tanto de los educadores como de la comunidad educativa; con el propósito de hacer de las escuelas, instituciones más inclusivas; capaces de ofrecer una oferta educativa de calidad, que le permita a la población con discapacidad intelectual contar con las 
herramientas y destrezas adecuadas, para mejorar su calidad de vida, convirtiéndolas en personas independientes y autónomas; tarea que representa un verdadero reto para el sistema educativo costarricense.

Se aborda el tema de inclusión educativa refiriéndose a algunos conceptos importantes dentro de dicho proceso, tales como: estudiantes con necesidades educativas especiales, educación especial, discapacidad, discapacidad intelectual, entre otros. También se trata la diversidad como una condición inherente al ser humano, lo que permite que estudiantes con y sin discapacidad compartan los mismos espacios y se interrelacionen positivamente, de manera que los unos aprenden de los otros $\mathrm{y}$ viceversa.

En el primer apartado se realiza un análisis de la responsabilidad que tienen todos los involucrados en el proceso de inclusión, al desarrollar un trabajo en equipo y contextualizado.

En el segundo apartado se hace un breve recorrido por la historia de la educación especial en Costa Rica como antecedente al proceso de integración, que desde 1974 dio sus primeros pasos.

El tercer apartado enumera algunos aspectos relacionados con las diferencias entre los conceptos de integración e inclusión y además se presenta la inclusión como una responsabilidad compartida, tanto por las autoridades educativas como por los docentes, padres, madres de familia y sociedad en general.

En el cuarto apartado se aborda el rol de los docentes, de la familia y de la sociedad en el proceso de inclusión y de cómo los aportes adecuados de cada uno de ellos repercutirán en el éxito del proceso mencionado.

Finalmente, el quinto apartado centra su atención en cómo se ha desarrollado la inclusión educativa en Costa Rica y cuáles han sido sus alcances.

De esta manera la inclusión educativa de estudiantes con necesidades educativas especiales asociadas a discapacidad inte- lectual, no sólo se refiere a tenerlos dentro de las aulas regulares, implica además una serie de cambios en el quehacer profesional docente, en sus actitudes y en el contexto educativo y social.

\section{La inclusión educativa es una responsabilidad de todos}

El proceso de inclusión educativa requiere del trabajo y del compromiso de todos sus actores, cuyo fin es la integración total a la comunidad educativa y a la sociedad, de los estudiantes con necesidades educativas especiales asociadas a discapacidad intelectual.

Antes de abordar la temática es importante definir algunos conceptos que se mencionan con frecuencia en el artículo. En el documento que aborda las Políticas, Normativa y Procedimientos para el Acceso a la Educación de los Estudiantes con Necesidades Educativas Especiales, se define la educación especial como el conjunto de apoyos y servicios disponibles para los estudiantes con necesidades educativas especiales, los cuales pueden ser requeridos de forma temporal o permanente (Ministerio de Educación Pública [MEP]. Costa Rica (2005).

En el mismo documento se conceptualiza los servicios de apoyo como las ayudas técnicas, el equipo, los recursos auxiliares, asistencia personal y servicios de educación especial (apoyo a la integración, terapia de lenguaje, trastornos emocionales, otros) que necesitan los estudiantes con necesidades educativas especiales, de manera que puedan acceder a una educación que garantice el máximo desarrollo de sus capacidades (Ministerio de Educación Pública [MEP]. Costa Rica (2005).

Paralelo a los conceptos anteriores, está el de alumno con necesidades educativas especiales, que se define en el documento Políticas, Normativa y Procedimientos para el Acceso a la 


\section{Educación de los Estudiantes con} Necesidades Educativas Especiales, como aquel discente que presenta dificultades en el aprendizaje por encima del promedio de los alumnos, que le impide acceder al currículo que le corresponde por edad; de forma tal que requiere de adecuaciones en una o varias áreas del currículo (Ministerio de Educación Pública [MEP]. Costa Rica (2005).

Dentro de las necesidades educativas especiales están las asociadas a algún tipo de discapacidad, una de ellas es el retraso mental, sin embargo, por el carácter peyorativo de dicha terminología y para efectos de este artículo se utilizará el concepto de discapacidad intelectual.

La discapacidad intelectual se define como "un estado particular de funcionamiento que comienza en la infancia, es multidimensional, y está afectado positivamente por apoyos individualizados" (Luckasson, citado por Verdugo, 2003, p. 15).

Así la discapacidad intelectual no se queda únicamente en una categoría diagnóstica, va más allá; al considerar primordialmente el valor del individuo como persona dentro de la sociedad, con derechos y responsabilidades.

Dentro del proceso de inclusión, los docentes de educación regular, tienen una gran responsabilidad; ya que serán quienes tendrán dentro de sus aulas y grupos a estudiantes con necesidades educativas especiales asociadas a discapacidad intelectual y los que promoverán dentro de su espacio de aula valores de tolerancia, solidaridad y cooperación.

A la par de los docentes de educación regular, están los de educación especial, quienes apoyan el proceso de inclusión; desarrollan un trabajo en conjunto con el docente de aula regular y hacen válido el derecho a educarse en el ambiente menos restrictivo; esto por cuanto serán ellos los que determinen en gran medida la aceptación o no de esos estudiantes en el centro educativo, en el grupo de pares y en las familias; convirtiéndose en una responsabilidad compartida.
En un centro educativo inclusivo el derecho a la educación que tienen los estudiantes con necesidades educativas especiales asociadas a discapacidad intelectual, no se limita únicamente a que asistan a la misma institución donde están sus vecinos o amigos, va más allá; implica una interrelación adecuada con el contexto: compañeros, compañeras, docentes, administrativos, padres y madres de familia, entre otros.

Una institución inclusiva es aquella en la que no existe ningún tipo de discriminación; se caracteriza por el trabajo colaborativo tanto entre docentes, como entre los mismos estudiantes y el resto de la comunidad educativa; de forma tal que se promueve el éxito de todos los alumnos en su proceso de enseñanza y aprendizaje.

En el contexto de aula las interrelaciones entre docentes, estudiantes con y sin discapacidad deben estar basadas en el respeto, la tolerancia y la igualdad de oportunidades, en la que todos gocen de los mismos derechos; sin obviar las necesidades particulares.

En un ambiente inclusivo es primordial el respeto y aceptación de todas las personas, independientemente de sus características particulares. Al respecto Soto (2003, p. 3) menciona que al hablar de inclusión se habla de

... tolerancia, respeto y solidaridad, pero sobre todo, de aceptación de las personas, independientemente de sus condiciones. Sin hacer diferencias, sin sobreproteger ni rechazar al otro por sus características, necesidades, intereses y potencialidades, y mucho menos, por sus limitaciones.

También Arnaiz hace referencia a que la inclusión en los centros educativos se torna difícil porque “... supone reconocer y respetar a todos los grupos culturales como alternativas válidas y no sólo como substratos marginados ..." (2003, p. 172).

Ambos autores son claros al afirmar que la inclusión implica no sólo aspectos 
axiológicos, porque también se necesita del compromiso y de la convicción de las personas, al creer y aceptar que la inclusión es la respuesta adecuada para hacer de las escuelas y de la sociedad en general, ambientes justos y equitativos. Es más que tolerancia, es la aceptación y el respeto por el otro.

Son muchas las investigaciones realizadas en Latinoamérica que han demostrado que los estudiantes con necesidades educativas especiales asociadas a algún tipo de discapacidad, se pueden desarrollar de manera integral en un aula regular, recibiendo los apoyos necesarios; por ejemplo los trabajos realizados por García (2005); Peña (2005); Romero y Lauretti (2006) y Soto (2003), coinciden en que dicha población puede ser integrada e incluida en ambientes educativos regulares, en los cuales exista respeto y aceptación por las diferencias y la diversidad.

Actualmente el término diversidad se está aplicando en la inclusión educativa para ampliar la atención a la población estudiantil, posean o no algún tipo de discapacidad.

El término diversidad se está utilizando para dar mayor amplitud al de educación especial, porque abarca no sólo aspectos referentes a las necesidades educativas especiales, sino que además incluye la diversidad cultural, lingüística, discapacidad, superdotación, entre otros aspectos (Arnaiz, 2004).

En la inclusión se defiende el derecho que tienen todas las personas de recibir una educación en igualdad de oportunidades, independientemente de que se posea o no una discapacidad; por lo tanto, las instituciones educativas que opten por la inclusión, deben ser capaces de atender la diversidad del alumnado y promover la justicia social, por medio de la puesta en práctica de valores que permitan la sana convivencia.

Así, el papel de las escuelas será el de ofrecer a cada discente los insumos y herramientas acordes a sus características particulares, de manera que todos y cada uno de los estudiantes de la comunidad educativa se sientan acogidos, seguros y convencidos de que lograrán sus metas; en este sentido, De La Torre y otros (1998, p. 61), citando a Smylie (1988) menciona el contexto interactivo de la escuela en la que "hay una relación cordial y de intercambio entre profesores que tratan temas educativos y de enseñanza en un clima positivo, amigable, que estimula la experimentación y en el que los directivos supervisan y animan para que todos se sientan aceptados y respetados".

La puesta en práctica de un proyecto educativo capaz de entender y atender de forma pertinente las diferencias y la diversidad de todos los discentes, es el elemento clave en el proceso de inclusión educativa.

A pesar de que en Costa Rica hay estudiantes con necesidades educativas especiales, asociadas a discapacidad intelectual, matriculados en las aulas regulares de primero y segundo ciclo, esto se ha quedado en una simple integración.

La integración fue el modelo que favoreció el acceso a escuelas ordinarias de alumnos con necesidades educativas especiales asociadas a discapacidad, no así la participación completa de esa población en la vida de la escuela y de la comunidad (Arnaiz, 1997).

En Costa Rica la integración de estudiantes con necesidades educativas especiales asociadas a discapacidad intelectual ha significado un gran avance y una oportunidad para estos estudiantes y sus familias, ya que de esta forma han logrado tener acceso a ambientes educativos menos restringidos, a una vida lo más normal posible y a recibir una educación en igualdad de oportunidades.

Sin embargo, no significa que en Costa Rica no se estén realizando esfuerzos para pasar de la integración a la inclusión, de hecho se ha seguido un largo y empinado camino; sin embargo, no basta con tener dentro de las aulas regulares a estudiantes con necesidades educativas especiales 
asociadas a discapacidad intelectual, lo primordial es que estén incluidos, es decir, que se les reconozca y se les valore como personas y además, que el centro educativo responda a las necesidades, intereses y expectativas de dichos discentes y del resto del alumnado.

Con base en la experiencia profesional de la autora, se puede afirmar que se están haciendo importantes aportes en cuanto a información y sensibilización se refiere; sin embargo, es una tarea que apenas empieza y que requiere del compromiso de cada uno de los entes involucrados, para hacer de la inclusión un proceso exitoso.

Por lo tanto, la inclusión educativa implica actitudes de respeto y de aceptación, otorgando igualdad de oportunidades a las personas que presentan necesidades educativas especiales, asociadas a discapacidad intelectual.

Aunado a lo anterior, también se les otorga el derecho que tienen a la educación, al trabajo, a la recreación, al ocio y a la expresión de su sexualidad, entre otros aspectos.

Por consiguiente, la importancia de abordar este tema está en que cada día son más las personas que presentando necesidades educativas especiales asociadas a discapacidad intelectual y que conocen sus derechos, apelan por una igualdad de oportunidades en todos los contextos: social, educativo, familiar y laboral. Ello ha sido el resultado de cambios en la educación especial, en la que se pasó de la ayuda y de la asistencia, al respeto por la individualidad, las características y necesidades particulares.

Es así como la escuela se convierte en uno de los espacios de inclusión más importantes; por lo que pareciera que es el sistema educativo el mejor capacitado para informar y sensibilizar de forma pertinente a la población y además, el responsable de crear una conciencia de aceptación y de equidad hacia las personas que presentan algún tipo de discapacidad, para lo cual es esencial el trabajo coordinado y en equipo.
Podría afirmarse que la educación inclusiva tiene su punto de inicio con la Declaración de Salamanca, en 1994; en la que se le pide y se insta a los gobiernos a "dar la más alta prioridad política y presupuestaria al mejoramiento de sus sistemas educativos para que puedan incluir a todos los niños y niñas, con independencia de sus diferencias o dificultades individuales, ..." (Organización de las Naciones Unidas para la Educación, la Ciencia y la Cultura [UNESCO] y otros, 1994, p. ix).

De forma paralela, la Conferencia Mundial sobre Educación para Todos (UNESCO, 2000), la Declaración de Conchabamba (UNESCO, 2001) y la Declaración de Montreal sobre la Discapacidad Intelectual (Organización Panamericana de la Salud/Organización Mundial de la Salud [OPS/OMS], 2004); coinciden en que todas las personas tienen el derecho de aprender y de mejorar su calidad de vida, para contribuir al desarrollo de la sociedad.

Los primeros pasos que ha dado Costa Rica en materia de educación especial y de integración y que han sido la antesala para el inicio del proceso de inclusión educativa se detallan en el siguiente apartado.

\section{La educación especial en Costa Rica y el proceso de integración}

Con el fin de ubicar a las personas interesadas en el tema, se hace referencia a la educación especial desde sus inicios en Costa Rica. A partir del año 1939 se evidencian en este país los primeros movimientos en Educación Especial y se definen las políticas educativas que han ido fortaleciendo este tipo de educación.

La atención que se le da en ese momento a la población que presenta algún tipo de discapacidad, es asistencial y se considera necesaria la intervención de profesionales para rehabilitar a la persona. 
El Dr. Fernando Centeno Güell, inicia en 1939 y de forma privada la atención de personas con discapacidad; es hasta el año 1940, que el Estado asume la educación especial. La escuela atendió a personas con retraso mental, con deficiencias visuales y deficiencias auditivas. En la década de los 60 se crearon otras escuelas de educación especial en diferentes regiones del país.

La Universidad de Costa Rica, por su parte, ofrece desde 1962 la carrera de educación especial, con el propósito de ofrecer al sistema educativo profesionales capacitados en el área. En el año 1974 establece la carrera de educación especial con énfasis en retardo mental, problemas de aprendizaje y trastornos de la comunicación; posteriormente crea la especialización en trastornos emocionales y deficiencias visuales.

También la Universidad Nacional se une a la formación de profesionales en el área de educación especial, es así como en los años 1973 y 1974 capacita a los asesores de problemas de aprendizaje con el fin de que brinden un mejor servicio.

En 1974 se inicia la creación de las Aulas Diferenciadas, hoy llamadas Aulas integradas; las cuales responden a los principios de normalización y de integración. Estas se encuentran ubicadas dentro de las escuelas regulares y de esta forma se dan los primeros pasos en materia de integración.

En las aulas integradas se atienden estudiantes con retraso mental leve y moderado; sin embargo, en lugares donde no existen escuelas de enseñanza especial, las aulas integradas pueden atender casos más severos.

En 1978 se inicia la atención de adolescentes con retraso mental, en el III ciclo de la Educación Técnica, específicamente en colegios prevocacionales.

A partir de 1990 en el nivel de preescolar se inicia la integración de niños y niñas con retraso mental.

En 1986 se realiza un análisis de la situación de la educación especial, lo cual repercutió en una reestructuración administrativa y en la ampliación de los servicios de apoyo.

En el año 1996 se aprueba la Ley 7600 "Igualdad de Oportunidades para las Personas con Discapacidad", en la que se establece el derecho que tienen las personas que presentan algún tipo de discapacidad, a estar en el ambiente menos restringido posible, además de que se pretende con ello llegar a la construcción de "escuelas inclusivas" o "escuelas para todos", es decir, de centros educativos que tengan como propósito la educación de todos los alumnos y alumnas en las aulas ordinarias, independientemente de que tengan o no algún tipo de discapacidad.

A partir de ese año se llevan a cabo una serie de acciones tendientes a sensibilizar a la población, lo cual ha permitido una mayor integración de estudiantes provenientes de escuelas de enseñanza especial a las aulas integradas.

Dicha sensibilización abarca también a los docentes y estudiantes de primero y segundo ciclos, con respecto a ofrecer una atención adecuada a los niños y niñas que presentan algún tipo de discapacidad.

Según Marín (2002), en Costa Rica existen actualmente estudiantes con alguna discapacidad integrados en las aulas regulares, en las cuales se les garantiza la atención adecuada de sus necesidades, por medio de adecuaciones curriculares (no significativas, significativas, de acceso) y de docentes de apoyo; sin embargo, en muchas ocasiones la integración ha quedado en una simple integración física y no en una integración social. De esta forma, se hace necesario pasar de un aula de integración a un aula de inclusión, en la que niños y niñas con y sin discapacidad asistan, participen e interactúen y en la que el protagonista sea el estudiante.

La integración escolar ha sido el primer paso para que los estudiantes que presentan algún tipo de discapacidad gocen de igualdad de oportunidades; pero teniendo presente, que toda la labor educativa se desarrolla a partir de las necesidades específicas del discente. 
El origen de la integración escolar tiene sus bases en tres principios: normalización, sectorización e individualización (Lou y López, 1998). El primero pretende llegar a la máxima normalización de los niños y niñas con necesidades educativas especiales, no sólo en el ambiente escolar, sino también en el social y laboral. El objetivo del principio de normalización es que el niño o niña desarrolle un tipo de vida lo más normal posible.

Marín (2002, p. 73) señala que el principio de normalización: “... pretende poner al alcance de las personas con algún tipo de discapacidad, condiciones de vida lo más parecidas posibles a las formas y condiciones de vida del resto de la sociedad".

La normalización implica aceptar a la persona tal y como es, reconocerle sus derechos y brindarle los apoyos necesarios para que logre desarrollar sus aptitudes.

Posterior al principio de normalización y no por ello menos importante, está el principio de individualización, el cual hace referencia a la necesidad de individualizar tanto la metodología como las programaciones educativas; las cuales deben ajustarse a las particularidades de cada estudiante. Para ello se requiere de un currículo abierto y flexible que responda en forma idónea a dichas necesidades, lo cual es posible, por medio de la aplicación de adecuaciones curriculares; unido a ello está la actitud profesional y comprometida de los docentes de aula regular, los de educación especial y demás miembros de la comunidad educativa.

Si bien es cierto, la inclusión implica igualdad de oportunidades; ésta debe responder a las necesidades de todos y cada uno de los estudiantes y no solamente de aquellos que presentan discapacidad intelectual.

En cuanto a la definición del principio de sectorización, Lou y López (1998, p. 44), mencionan que es: "la aplicación del principio de normalización a la prestación de servicios al sujeto con necesidades educativas especiales en el entorno en que vive".
Por lo tanto, el principio de sectorización se refiere al derecho que tienen los alumnos y alumnas con necesidades educativas especiales a recibir en su propia comunidad la atención educativa pertinente, evitando así el desplazamiento de ésta población a lugares alejados de su entorno geográfico.

Con base en los principios citados, la integración se convierte en un tema complejo y para muchos difícil de abordar; ya que conlleva una serie de cambios que necesitan del compromiso de muchas personas.

La integración escolar de niños y niñas con necesidades educativas especiales ha pasado por varias etapas: primero se inició con el reconocimiento al derecho de educación de estas personas; luego se crean las instituciones de educación especial, dándose así una diferenciación y segregación de este tipo de población, seguido de ello se ubican aulas especiales en centros educativos regulares y por último, se presenta la integración plena, en la cual los niños y niñas con necesidades educativas especiales participan de los mismos espacios que el resto de sus iguales y el proceso educativo está dirigido a atender las necesidades que posee dicha población (Zabalza, 1994).

El concepto de integración se entiende como "un proceso donde la educación que se ofrece en las escuelas normales se hace más diferenciada y está dirigida a solucionar un abanico más amplio de necesidades del alumno" (Lou y López, 1998, p. 41).

Se hace evidente la necesidad de un único sistema educativo que ofrezca una educación capaz de atender la diversidad y particularidades del alumnado.

Por lo tanto, la integración escolar es un proceso que está dirigido a todos los estudiantes, va más allá del contexto escolar; ya que abarca también el entorno social y cultural.

El término integración surgió en los años sesenta, inmerso en un movimiento de luchas sociales que postulaba principios de derechos humanos, de justicia y de igualdad; es así como la integración tiene como 
uno de sus pilares, el derecho de todos los estudiantes de estar en un ambiente normalizado, en el que se garantice su futura integración social, participando activamente en la sociedad.

Blanco (1999), se refiere a la integración como un asunto de derechos, con criterios de justicia e igualdad y cuyo fin es alcanzar una educación de calidad para todos. También Marín (2002) menciona que la integración es el proceso mediante el cual se coloca a un estudiante con necesidades educativas especiales asociadas a discapacidad en un aula regular, brindándole los apoyos adecuados, y coincide con la autora anterior en que deben gozar de los mismos privilegios y derechos que tienen los estudiantes que no poseen discapacidad.

De esta forma, el proceso de integración no se queda únicamente en el nivel educativo, sino que también involucra a la familia, por lo que la tarea del hogar y la escuela debe ser la de realizar una labor conjunta, con el propósito de incorporar totalmente a la persona con necesidades educativas especiales asociadas a discapacidad, a la vida familiar, escolar, social y laboral.

Costa Rica es parte de un proceso de integración desarrollado en Latinoamérica, cuyo propósito ha significado la incorporación de personas con necesidades educativas especiales a la comunidad; al respecto Romero y Lauretti (2006, p. 348) mencionan: "La integración educacional es entonces válida, satisfaciendo las necesidades generales de las personas con discapacidad en un aula regular y las específicas en su interacción con el docente especialista”.

A pesar de que la integración es un proceso que ha permitido la incorporación de los estudiantes con necesidades educativas especiales asociadas a discapacidad intelectual en las aulas de educación regular, y por consiguiente validar el derecho que tienen a la educación en ambientes "normalizados", ello no ha sido suficiente, ya que aún se requieren cambios en el sistema educativo en cuanto a la concepción de las necesidades educativas especiales, de manera que sean abordadas como parte de la diversidad.

Con frecuencia en el área de educación especial se ha utilizado el concepto de diversidad para referirse a los discentes que tienen necesidades educativas especiales, sin embargo, en la actualidad se le está dando un giro, de forma tal que abarca otros aspectos relacionados con la diversidad cultural como: etnia, religión, género y cualquier situación de riesgo en los estudiantes.

Arnaiz (2004), propone que el concepto de diversidad posee una acepción más amplia, cuya atención es responsabilidad de todos y asume que por naturaleza los seres humanos son diversos; de manera que en los diferentes contextos debe existir un cambio de actitudes y de valores hacia lo que es diferente. Así la educación tiene que responder a una realidad diversa.

Otra autora que se refiere al término diversidad es Meléndez (1999/2002, p. 23), quien menciona: "la diversidad responde a un concepto universal, bajo el cual se ampara la idea de que los seres humanos solemos diferir en muchos aspectos personales y culturales como el género, la nacionalidad, la etnia, la religión, la preferencia política, las formas de conocer el mundo". Señala también, que el concepto de diversidad implica que no se obligue a seguir estándares de comportamiento y además propone que las diferencias no deben ser la base para establecer jerarquías, sino todo lo contrario, reconocer que equitativamente todas las identidades valen.

Desde esta perspectiva la diversidad es inherente al ser humano y por lo tanto, el sistema educativo debe responder a la heterogeneidad del alumnado, evitando así la exclusión y la segregación.

$\mathrm{Al}$ incluir el aspecto de diversidad en el proceso de integración, se ha tratado de mejorar la oferta educativa de los discentes que presentan algún tipo de discapacidad, lo cual no significa que no existan tropiezos al llevarlo a la práctica. 
En el proceso de integración se han presentado algunas dificultades y ellas son señaladas por Blanco (1999), por ejemplo, se continúa con una atención individualizada y diferenciada por parte del especialista, como si éste fuese el único profesional capaz de atender al estudiante integrado. Además, se le brinda al estudiante integrado una serie de servicios y apoyos, que obviamente requiere, pero que lo ideal sería que también se les brindara al resto de los estudiantes que no pertenecen al programa de integración.

Es importante señalar que muchas veces la responsabilidad del estudiante integrado recae únicamente en el docente de apoyo y dicho apoyo lo recibe fuera del aula, por lo que el cambio de actitud por parte de los docentes y compañeros se hace más difícil; ya que se le separa del grupo para darle una atención especial y diferente, con lo que se le estaría negando el derecho que tiene a una educación en igualdad de oportunidades.

Pareciera entonces que la integración se ha quedado en un nivel físico, cuyo principal objetivo tiene que ver con la socialización; dejando de lado la parte educativa como proceso de enseñanza y aprendizaje, subestimando así sus capacidades y negándole al estudiante con necesidades educativas especiales asociadas a discapacidad intelectual el derecho a recibir una educación de calidad.

De acuerdo con lo anterior, la respuesta adecuada en la atención de los estudiantes con necesidades educativas especiales asociadas a discapacidad intelectual, es la integración total; es decir, la incorporación de dicha población en los diferentes contextos: familiar, educativo, comunal y laboral.

La educación inclusiva requiere del desarrollo de actitudes que fomenten el respeto y la valoración por las diferencias, ya que uno de los grandes obstáculos con los que se enfrenta, es la gran cantidad de estereotipos y prejuicios que existen en torno a las necesidades educativas especiales asociadas a algún tipo de discapacidad.
Así, se hace evidente la necesidad de que cada institución desarrolle procesos educativos de inclusión tendientes a detectar las necesidades de sus estudiantes, comprenderlas y mejorarlas, lo cual permitirá una labor conjunta y la toma de decisiones por medio del consenso de padres y madres de familia, docentes, estudiantes, directores y sociedad en general.

El desarrollo integral de un estudiante con discapacidad intelectual no es una tarea fácil, requiere del apoyo y del compromiso de todos los componentes involucrados en el proceso educativo y de una mente abierta hacia lo que implica el concepto de diversidad.

\section{La inclusión: responsabilidad compartida}

Paralelo al proceso de integración educativa está el de inclusión; ambos se interrelacionan, pero no son sinónimos. Como se señaló anteriormente, la integración ha sido un movimiento que ha permitido el acceso y la participación de las personas con necesidades educativas especiales asociadas a alguna discapacidad, al sistema educativo regular.

Sin embargo, la integración se ha detenido en el nivel físico, es decir, no hay una interrelación entre los entes involucrados en dicho proceso y por lo tanto, no hay una integración total; es así como surge el concepto de inclusión educativa, que es mucho más amplio que el de integración y que abarca no sólo el derecho a la educación en ambientes "normalizados", sino que implica una serie de cambios a nivel macro y micro.

Las instituciones educativas comprometidas con el proceso de inclusión tienen que ser concientes y capaces de atender la diversidad del alumnado, brindándoles igualdad de oportunidades y experiencias de aprendizaje enriquecedoras, contextualizadas y aplicables a la realidad. 
Por lo tanto, la inclusión educativa sería la cúspide de un proceso de concienciación pertinente que involucraría un cambio de concepción desde el nivel educativo macro al nivel micro; cuyos componentes tendrían su "cuota" de responsabilidad para hacer que las escuelas inclusivas sean una realidad y un derecho de todos.

En Costa Rica la inclusión educativa aún no es una realidad, sin embargo, no se pueden obviar los grandes esfuerzos que se han realizado en el Ministerio de Educación Pública (M.E.P), por medio de las Asesorías Regionales de Educación Especial, para promover la integración de estudiantes con necesidades educativas especiales asociadas a discapacidad intelectual a las aulas regulares. Dichos estudiantes gozan de los mismos derechos que el resto de sus compañeros, por medio de la aplicación de adecuaciones significativas; lo cual permite adaptar el currículo oficial a las necesidades particulares del estudiante.

La escuela inclusiva se centra en la atención integral de todos los estudiantes con y sin necesidades educativas especiales, por lo tanto, los centros educativos deben transformar su estructura y funcionamiento curricular, de manera que respondan de forma pertinente a las necesidades educativas de todos, dando como resultado el éxito en el aprendizaje.

La educación inclusiva debe visualizarse como una forma de atender las necesidades educativas de cualquier estudiante y como el medio capaz de garantizar a los alumnos que presentan alguna discapacidad, de tener los mismos derechos que el resto de sus compañeros escolarizados en una escuela regular; en otras palabras y como lo señala Arnaiz (2002, p. 16) “...que todos sean ciudadanos de derecho en los centros regulares, bienvenidos y aceptados; formen parte de la vida de los mismos, y vistos como un reto para avanzar".

Un centro educativo que promueva la inclusión debe permitirle al estudiante que presenta necesidades educativas especiales asociadas a discapacidad intelectual, la posibilidad de aprender y convivir con sus iguales en diferentes contextos, evitando así la segregación y construyendo una sociedad más justa y equitativa.

Por ello es necesario que la comunidad educativa se informe y reflexione sobre la importancia de conocer y promover una educación inclusiva, en igualdad de oportunidades y de acceso para todos, permitiendo la adaptación y adecuación del currículo a las necesidades que presenta cada estudiante.

El currículo de las escuelas inclusivas debe caracterizarse por ser abierto y flexible, capaz de aceptar y generar cambios; debe existir un equipo de trabajo lo suficientemente organizado y comprometido con las necesidades educativas especiales entendiéndolas como parte de la diversidad; una diversidad que incluye además de las necesidades educativas especiales, los niños y niñas de la calle, de diferentes etnias, de diferentes estratos sociales, de diferentes ocupaciones, entre otros.

El papel de los diferentes actores en el proceso de inclusión es primordial, para hacer que el mismo sea una realidad en las aulas de primaria.

\section{Papel de los educadores, de la familia y de la sociedad}

Es necesario cambiar la concepción de necesidades educativas especiales asociadas a algún tipo de discapacidad, no sólo la que tiene la comunidad educativa, sino también la que posee la sociedad, ya que falta mucho camino por recorrer y aún el contexto social no está preparado para aceptar y compartir en un mundo diverso y diferente.

El papel de los educadores es fundamental, al ser ellos los que en gran medida determinen el éxito o fracaso del proceso de inclusión educativa, ya que sus actitudes positivas o negativas en dicho proceso, se verán reflejadas en su práctica educativa. 
Por ello, la institución educativa requiere de un trabajo en equipo, de manera que cuando surjan las dificultades, las mismas sean analizadas y evaluadas por el grupo de docentes, para que las decisiones sean tomadas en conjunto, procurando siempre la atención adecuada y pertinente de las necesidades educativas especiales en los diferentes contextos: educativo, social y laboral.

Los docentes por su parte, pueden y deben utilizar estrategias metodológicas y de evaluación variadas, que les permitan a los discentes con necesidades educativas especiales asociadas a discapacidad intelectual, tener acceso a una oferta educativa acorde a sus necesidades específicas.

Por su parte, los docentes de educación especial tienen la responsabilidad de formar e informar acerca de lo que es la integración, la inclusión, la relación entre ambos procesos y sus implicaciones teóricas y prácticas; de manera que exista sensibilización en la comunidad educativa $\mathrm{y}$ en la sociedad en general, en lo que a atención de necesidades educativas especiales asociadas a discapacidad intelectual se refiere.

Primero que todo, es necesario un cambio de actitud y fomentar el trabajo en equipo; en el que el aporte de cada miembro se toma en cuenta para avanzar hacia una educación inclusiva.

Con el fin de favorecer el cambio de actitudes en los docentes de enseñanza regular, las pasantías nacionales serían una alternativa, en la que haya intercambio entre docentes de educación primaria y docentes de educación especial.

En cuanto al componente familiar, es imprescindible hacer realidad el derecho que tienen de participar y colaborar en el proceso de enseñanza y aprendizaje de sus hijos/hijas y en la toma de decisiones que les afecten.

Es en el núcleo familiar donde el estudiante con necesidades educativas especiales asociadas a discapacidad intelectual, desarrolla sus primeras interrelaciones y lazos afectivos; que en gran medida le permitirán adquirir herramientas necesarias para su relación con otras personas ajenas a su entorno familiar.

Los aportes que la familia puede ofrecer a los profesionales en educación, son muchos y valiosos; éstos permitirán llevar a cabo una labor conjunta y coordinada; en beneficio del desarrollo integral del estudiante con necesidades educativas especiales, asociadas a discapacidad intelectual.

Por lo tanto, la familia debe estar informada y hacer efectivos los derechos que poseen los estudiantes con necesidades educativas especiales asociadas a discapacidad intelectual, además de contribuir a la divulgación de actitudes inclusivas.

El papel de la familia como ya se ha mencionado, es fundamental, ya que puede apoyar y colaborar en el proceso de inclusión en un contexto diferente al educativo. El profesional en educación puede planificar con la familia un programa de trabajo pertinente, de manera que les ayude no sólo a solucionar posibles problemas que surjan en la convivencia del hogar, sino también la puesta en práctica de conductas inclusivas en su entorno familiar.

En consecuencia, la educación solicita la participación y colaboración de la familia en el proceso educativo de sus hijos e hijas con necesidades educativas especiales asociadas a discapacidad intelectual, a pesar de que ambos abarcan contextos y roles diferentes, ambos se interrelacionan y tienen metas en común.

En cuanto al papel de la sociedad, este es fundamental para lograr escuelas inclusivas, ya que tanto los centros educativos como las comunidades, deben poseer actitudes de respeto y aceptación por las diferencias.

Una sociedad informada es una sociedad culta y sensible. El conocimiento de las necesidades educativas especiales, asociadas a discapacidad intelectual, le permitirá al contexto social aceptar, tolerar y creer en estas personas como individuos capaces de realizar muchas actividades y de hacerlas 
correctamente; algunas requerirán de apoyos permanentes, otras no, sin embargo, se les deben ofrecer las adaptaciones necesarias para llevar una vida lo más normal posible.

El grupo social debe brindarles las condiciones óptimas, respetando siempre sus características particulares y promoviendo su autonomía y vida independiente. Lo que necesitan son oportunidades, no la lástima ni la compasión.

La comunidad educativa y la sociedad en general están inmersas en el propósito principal de la inclusión, el cual consiste en hacer efectivo el derecho a la educación que tienen todos los estudiantes, en igualdad de oportunidades y de participación; por lo que el alumnado con necesidades educativas especiales asociadas a discapacidad intelectual tiene derecho a educarse en un ambiente normalizado que le asegure su completa integración en la sociedad.

En Costa Rica es importante llevar a cabo un proceso de concienciación a nivel educativo y a nivel social, de forma tal que se comprenda y se fomente una sociedad de respeto y de tolerancia por las diferencias; permitiendo el acceso a la educación y el derecho al aprendizaje de todas las personas, independientemente de la necesidad educativa especial que posean. Al respecto Blanco (1999, p. 10) afirma:

Es preciso, por tanto, que se produzca un cambio cultural para que las diferencias se valoren como un elemento positivo y una oportunidad para el enriquecimiento de los procesos de enseñanza y aprendizaje, y no como un obstáculo o algo negativo. Para ello, es fundamental desarrollar una intensa actividad de información y sensibilización a toda la comunidad educativa y a la sociedad, en la que los medios de comunicación social pueden jugar un rol fundamental.

Uno de los elementos que menciona la autora para lograr un adecuado proceso de sensibilización, es el de los medios de comunicación social, ya que ellos pueden desarrollar estrategias de difusión que promuevan el respeto a la diversidad, la tolerancia por las diferencias y la no discriminación.

De acuerdo con lo anterior la educación inclusiva se convierte en un gran reto, en el que los elementos involucrados intervienen y participan responsablemente. En Costa Rica, el sistema educativo está avanzando hacia la construcción de escuelas de y para la inclusión, al incorporar dentro de las aulas regulares estudiantes con algún tipo de discapacidad y brindándoles la atención adecuada, por medio de docentes de apoyo, profesionales en el área de la educación especial y sus diferentes ramas.

\section{Inclusión educativa en Costa Rica}

El derecho a la educación se encuentra establecido en la Declaración de los Derechos Humanos (s.f.) y en las políticas y planes educativos de los países, por lo cual es responsabilidad de cada uno validar ese derecho y ofrecer a la población estudiantil una educación adecuada y de calidad, independientemente de las características individuales.

Para llevar a la práctica lo anterior, en Costa Rica se han realizado las acciones pertinentes para establecer los fundamentos legales que permitan la igualdad de oportunidades de los estudiantes con necesidades educativas especiales asociadas a algún tipo de discapacidad.

Desde diferentes ámbitos y en especial desde el educativo, la Ley 7600 Igualdad de Oportunidades para las Personas con Discapacidad (Asamblea Legislativa, 1996), ha permitido legalizar la inclusión de niños y niñas con necesidades educativas especiales a los diferentes ciclos de la Educación General Básica, de manera que sus necesidades sean atendidas en cualquier ciclo educativo.

Con la aprobación de la Ley 7600 se garantiza a los discentes los servicios de apoyo que sean pertinentes (terapia de lenguaje, problemas emocionales y de conducta, problemas de aprendizaje) para facilitar su proceso de enseñanza y aprendizaje. 
Así, el centro educativo debe ofrecer los servicios y apoyos necesarios para atender la diversidad y satisfacer las necesidades del estudiante respetando su individualidad.

Las escuelas deben tener claro que el currículo debe ser funcional, debe promover el desarrollo integral de la persona, además de estar dirigido a la enseñanza de destrezas utilizadas en la vida diaria, que le permitan desenvolverse en la sociedad de la forma más independiente posible.

La educación inclusiva también produce beneficios, no sólo para el estudiante con necesidades educativas especiales asociadas a discapacidad intelectual, sino también para el resto del grupo; ya que aprenden a aceptar las diferencias, a compartir sus espacios y a valorar y respetar la diversidad.

En Costa Rica aún falta mucho camino por recorrer, ya que son varias las instituciones educativas públicas y privadas que se niegan a recibir y atender dentro de sus aulas, a estudiantes con necesidades educativas especiales asociadas a discapacidad intelectual.

Lo anterior pone en evidencia la falta de claridad que existe en muchos de los elementos involucrados en el proceso, en cuanto a la atención adecuada de las necesidades educativas especiales asociadas a discapacidad intelectual y en cuanto a la existencia de una legislación específica que promueve la integración de estos estudiantes a las aulas regulares de primero y segundo ciclos de la Educación General Básica.

El sistema educativo costarricense se ha quedado en el nivel de integración física, en el cual el estudiante se coloca en un aula regular y recibe generalmente fuera del aula los apoyos que requiere, dándose así una atención diferenciada y segregada.

$\mathrm{Al}$ respecto Soto (2003, p. 2) afirma:

No se puede hablar de inclusión en tanto no se haya realizado un análisis y discusión de los diferentes procesos en que se ha enmarcado la experiencia educativa de las personas con necesidades educativas especiales, así como los procesos de formación de los docentes y otros profesionales relacionados con estas personas.

Por ello, una escuela inclusiva tiene que estar dispuesta a realizar cambios sustanciales en su quehacer diario, de manera que logre adaptar el proceso de enseñanza y aprendizaje a todos los estudiantes y fomentar una educación para todos.

En un centro educativo a favor de la inclusión, el desarrollo integral de un estudiante con necesidades educativas especiales, asociadas a discapacidad intelectual, requiere del apoyo de un equipo interdisciplinario que contribuya a hacer realidad una escuela para todos; en la que se le facilite al estudiante el desarrollo de habilidades para la vida diaria y para el trabajo, lo cual le permitirá aumentar su nivel de independencia y de autonomía, formando así una persona capaz de elegir y de tomar sus propias decisiones.

A pesar de que en Costa Rica existen muchas instituciones educativas que cuentan con equipos interdisciplinarios, los mismos son ajenos al proceso de inclusión de estudiantes con necesidades educativas especiales asociadas a discapacidad intelectual.

El trabajo de estos equipos está dirigido a poner a funcionar dentro de los centros educativos de atención prioritaria, los mejores recursos, tanto humanos como materiales, en función de los alumnos y alumnas más vulnerables a la pobreza. Su filosofía de trabajo se basa en hacer una verdadera justicia social, donde los principios democráticos se visualizan como instrumento de desarrollo individual y social, con el propósito de formar una colectividad más productiva, que contribuya con el desarrollo social, económico y cultural del país.

Lo anterior podría ampliarse, de forma tal que, dentro de su filosofía de justicia social se incluya la atención, el apoyo y el seguimiento adecuado a aquella población que presenta algún tipo de 
discapacidad, en conjunto con los servicios de educación especial, los docentes de aula regular y el personal administrativo de la institución.

Algunos países como Uruguay, México, Venezuela; también países europeos como Bélgica, Suiza, Noruega, Holanda, entre otros; han tenido prácticas eficaces en torno a la atención de las necesidades educativas especiales en el aula regular. El trabajo realizado se basa en aspectos como enseñanza cooperativa, aprendizaje cooperativo, solución cooperativa de conflictos y agrupamientos heterogéneos; todo ello en el marco de un enfoque educativo más personalizado, aspectos que definitivamente podrían ser adaptados al sistema educativo costarricense.

Lo expuesto en este artículo no se puede lograr sin el compromiso y apoyo de los docentes, siendo ellos los principales responsables de realizar los cambios y ajustes necesarios; ya que son los que finalmente harán posible la inclusión, al concretarla en sus salones de clase.

La inclusión de estudiantes con necesidades educativas especiales asociadas a discapacidad intelectual es una responsabilidad conjunta, en la que tanto, la familia, la comunidad educativa y la sociedad en general, pueden y deben aportar sus ideas en beneficio no sólo de la población estudiantil mencionada, sino también de ellos mismos, forjando una colectividad basada en los valores de justicia y equidad.

\section{Referencias bibliográficas}

Agencia Europea para el Desarrollo de la Educación Especial. (2003). Educación inclusiva y prácticas en el aula. Extraído el 24 de febrero de 2008 de http://www.european-agency. org/publications/agency_publications/ ereports/CP/CP_spain.doc

Arnaiz, P. (1997). Integración, segregación, inclusión. En P. Arnaiz y R. de Haro (Eds.), 10 años de integración en España: análisis de la realidad $y$ perspectivas de futuro: actas de la XXII Reunión científica anual de la Asociación Española para la Educación Especial (AEDES), Murcia, del 9 al 12 de noviembre de 1995. (pp. 313-354). España: Universidad de Murcia, Servicio de Publicaciones. Extraído el 10 de julio de 2002 de http://dialnet.unirioja.es/ servlet/articulo?codigo $=307432$

Arnaiz, P. (2002, Mayo). Hacia una educación eficaz para todos: La educación inclusiva. Extraído el 4 de mayo de 2004 de

\section{www.congreso.gob.pe/ comisiones/2006/discapacidad/ tematico/educacion/inclusion.pdf}

Arnaiz, P. (2003). Capítulo V. Incluyendo a los excluidos: cómo hacer que la educación llegue a todos. En P. Arnaiz (Aut.), Educación inclusiva: Una Escuela para Todos (pp. 171249). España: Ediciones Aljibe.

Arnaiz, P. (2004). La educación inclusiva: dilemas y desafíos. Revista de Educación, Desarrollo y Diversidad, 7(2), 25-40. Extraído el 24, mayo, 2007 de http://www.aedes-nacional. com/revista7septiembre2004.htm

Asamblea Legislativa (1996, Mayo 29). Ley 7600 Igualdad de Oportunidades para las Personas con Discapacidad. En: La Gaceta Diario Oficial. Año CXVII, $N^{o}$ 102. Extraído el 27 de abril, de 2007 de www.oit.or.cr/bidiped/legislacion/ley7600.htm

Blanco, R. (1999, Abril). La educación inclusiva en América Latina: Realidad y perspectivas. [Conferencia Magistral]. En R. Blanco (Aut.), Hacia una escuela para todos y con todos: Boletín Proyecto Principal de Educación en 
América Latina y el Caribe, 48 (pp. 55-73). Santiago, Chile: UNESCO.

Declaración Universal de los Derechos Humanos. (s.f.). Adoptada y proclamada por la Resolución de la Asamblea General 217 A (iii) del 10 de diciembre de 1948. Extraído el 27 de agosto de 2007 de http://www.un.org/ spanish/aboutun/hrights.htm

De la Torre, S., Jiménez B., Tejada, J., Carnicero, P., Borrell, N. y Medina, J. L. (1998). Cómo innovar en los centros educativos. Estudio de casos. Madrid: Escuela Española, S.A.

García, V. (2005). Educación inclusiva: Un desafio para las escuelas de la comuna de San Pedro de la Paz. Extraído el 21 de octubre de 2006 de

http://www.innovemosdoc.cl/ diversidad_equidad/investigacion estudios/educacion_inclusiva.doc

Lou, M. A. y López, N. (1998). Bases psicopedagógicas de la educación especial. Madrid: Ediciones Pirámide.

Marín, M. G. (2002). Atención del niño excepcional. San José. Costa Rica. Editorial UNED.

Meléndez, L. (1999/2002). La inclusión escolar del alumno con discapacidad intelectual ( $2^{\circ}$ Reimpresión). Bogotá. Colombia. Proyecto editorial: Creamos alternativas.

Ministerio de Educación Pública [MEP]. Costa Rica. (2005). Centro Nacional de Recursos para la Inclusión Educativa. Compilación de disposiciones reglamentarias y lineamientos con relación a la atención de las necesidades educativas especiales de las y los estudiantes 1997-2005. San José, Costa Rica: Ministerio de Educación Pública: EDITORAMA.
Organización de las Naciones Unidas para la Educación, la Ciencia y la Cultura [UNESCO]. (2001, 5 y 7 de marzo). Declaración de Cochabamba y recomendaciones sobre políticas educativas al inicio del siglo XXI. En $L a$ Séptima Reunión del Comité Regional Intergubernamental del Proyecto Principal de Educación en América Latina y el Caribe [PROMEDLAC VII] (pp. 1-24). Bolivia. Extraído el 19 de agosto del 2004 de

http://www.unesco.cl/medios/ biblioteca/documentos/promedlac_ declaracion_recomendaciones cochabamba_esp.pdf

Organización de las Naciones Unidas para la Educación, la Ciencia y la Cultura [UNESCO] y Ministerio de Educación y Ciencia de España. (1994, 7 a 10 de Junio). Declaración de Salamanca y Marco de Acción para las necesidades educativas especiales. En Conferencia Mundial sobre Necesidades Educativas Especiales: Acceso y calidad (pp. i-xiii (páginas iniciales) y 1-47 (documento). Extraído el 12 de setiembre de 2005 de http://www.unesco.org/education/ pdf/SALAMA_S.PDF

Organización Panamericana de la Salud/Organización Mundial de la Salud [OPS/OMS]. (2004, 5 y 6 de Octubre). Declaración de Montreal sobre la Discapacidad Intelectual. En Conferencia Internacional OPS/ OMS de Montreal (pp. 1-16). Extraído el 11 de junio de 2007 de http:// www.uam.es/personal_pdi/stmaria/ sarrio/declaraciones\%20manifiestos/ Decl\%20Montreal.pdf

Peña, M. (2005). El ambiente de aprendizaje inclusivo en el aula. Una mirada a la colaboración entre pares en dos grupos integradores de primaria regular. REICE. Revista Electrónica 
Iberoamericana sobre Calidad, Eficacia y Cambio en Educación, 1(3), 817-822 Extraído el 21 de octubre, de 2006 de

http://www.ice.deusto.es/rinace/reice/ vol3n1_e/Pena.pdf

Romero, R. y Lauretti, P. (2006, Junio). Integración educativa de las personas con discapacidad en Latinoamérica Educere. La Revista venezolana de Educación. 33(10), 347-356. Extraído el 21 de octubre de

php?script $=$ sci_arttext\&pid=S1316-4
$\underline{\text { www.scielo.org.ve/scielo }}$
$\underline{\text { \&nrm }=\text { iso \&tlng }=\text { pt }}$

Schalock, R. y Verdugo, M. (2002). The concept of quality of life in human services: A handbook for human service practitioners. Washington, DC: American Association on Mental Retardation.

Schalock, R., y Verdugo, M. (2002/2003). The concept of quality of life in human services: A handbook for human service practitioners. Washington, D.C.: American Association on Mental Retardation. (Trad. Cast. M. A.
Verdugo y C. Jenaro. Calidad de vida. Manual para profesionales de la salud, educación y servicios sociales). Madrid: Alianza.

Soto, R. (2003). La inclusión educativa: Una tarea que le compete a toda una sociedad. Revista electrónica Actualidades Investigativas en Educación, 1(3), $1-16$.

UNESCO, (2000, 26 al 28 de abril). Marco de Acción de Dakar. Educación para todos: cumplir nuestros compromisos comunes. En Foro Mundial sobre la Educación. Dakar, Senegal (pp. 1-78). París: Graphoprint. Extraído el 24 de Julio del 2005 de http://www. unesco.org/education/efa/ed_for_all/ dakfram_spa.shtml

Verdugo, M. A. (2003). Análisis de la definición de discapacidad intelectual De la Asociación Americana sobre retraso mental de 2002. Siglo Cero: Revista Española sobre Discapacidad Intelectual, 205(34), 5-19.

Zabalza, M. (1994). Diseño y desarrollo curricular. Madrid, España: Ediciones Narcea. 
